\section{In Vitro Antimicrobial and Antioxidant Activities of Chitosan Oligosaccharides}

\author{
Ji-Young Kim ${ }^{1 \dagger}$, Kil-Nam Kim ${ }^{1 \dagger}$, Jong-Gwan $\mathrm{Kim}^{2}$, \\ Seong Chul Kim², Wook Jae Lee', and \\ Chang-Gu Hyun *
}

${ }^{1}$ Research Group for Cosmetic Materials, Jeju Biodiversity Research Institute (JBRI), Jeju Hi-Tech Industry Development Institute (HiDI), Jeju 699-943, Republic of Korea

${ }^{2}$ Kumpoong Bio Co., Ltd. Jeju 690-923, Republic of Korea

Received December 8, 2009; Accepted June 8, 2009

Key words: antibacterial activity, antioxidant activity; chitosan oligosaccharide, cytotoxicity

Chitinous materials such as chitin and chitosan are the second most abundant biopolymers on earth after cellulose. Chitin, an insoluble and linear homopolymer of linked 1,4- $\mathrm{N}$-acetylglucosamine, is an abundant, renewable, natural material present in cell walls of fungi and certain green algae, and it is the major component of the shells and exoskeletons of crustaceans and insects. Chitosan is a polycationic copolymer consisting of $\beta$ 1,4-linked 2-acetamido-D-glucose and $\beta$-1,4-linked 2-amino-Dglucose units. Crab and shrimp shell wastes are currently utilized as the major industrial source of biomass for large-scale production of chitosan. Chitosan, which is biodegradable, nontoxic and biocompatible, is particularly useful in many industry fields, including food, cosmetics, biomedicine, agriculture and environmental protection [Felt et al., 1998; Liu et al., 2007]. However, its high-molecular weight has limited its practical applications due to its insolubility above $\mathrm{pH} 6.3$ [Fernandes et al., 2008; Seo et al., 2008]. Therefore, recent studies on chitosan have investigated converting it to chitooligosaccharides (COS), because $\operatorname{COS}$ not only are water-soluble but also possess versatile functional properties. These COSs are generally produced via chemical, physical or enzymatic scission by

These authors contributed equally to this work.

*Corresponding author

Phone: +82-64-720-2811; Fax: +82-64-720-2801

E-mail: cghyun@jejuhidi.orkr

Abbreviations: COS, chitooligosaccharides; NBT, nitroblue tetrazolium

doi: $10.3839 / \mathrm{jabc} .2009 .015$ chitosanase and chitinase [Seyfarth et al., 2008].

In this study, we prepared three kinds of COSs with different molecular weights (COS-A, COS-B, COS-H) and a citrate derivative of COS-H via enzymatic scission (Fig. 1). The antibacterial and antioxidant activities of these COSs were then evaluated. The reported antibacterial effects seem to be closely related to molecular weight and degree of acetylation [Lee et al., 2002]. However, the results published so far have been contradictory: some authors reported that chitosan is more effective than COS in inhibiting bacterial growth, while others claimed that an increase in molecular weight decreases the activity of chitosan [Shahidi et al., 1999; Jeon et al., 2001; Liu et al., 2001; Zheng et al., 2004; Qin et al., 2006; Eaton et al., 2008; Fernandes et al., 2008]. These apparent contradictions must therefore be taken into account whenever antimicrobial assays are performed with COSs. The following food-borne and skin pathogens were used to test the antimicrobial activity of the COSs: Listeria monocytogenes ATCC 19115, Staphylococcus aureus ATCC 25293, Escherichia coli ATCC 25922, Vibrio parahaemolyticus ATCC 33844, Propionibacterium acnes ATCC 6919, Propionibacterium granulosum ATCC 25564, Malassezia furfur ATCC 14521, Staphylococcus epidermidis ATCC 12228, and Candida albicans ATCC 10231. Antimicrobial activity of COSs was measured by the paper disc diffusion method. The cultures were adjusted with sterile saline solution to optical density (O.D) $0.4\left(10^{6} \mathrm{CFU} / \mathrm{mL}\right.$ ). Filter paper (Whatman. No. 5, Whatman International Ltd, Piscataway, NJ) discs $(8 \mathrm{~mm}$ diameter) were impregnated with $2 \mathrm{mg} / \mathrm{mL}$ of the COSs, which were then aseptically applied to the surface of an agar plate at well-spaced intervals. Discs impregnated with sterile water were used as the negative control. The plates were incubated at $37^{\circ} \mathrm{C}$ for $24 \mathrm{~h}$, and growth inhibition zones, including the diameter of the discs, were measured. The sensitivity of food-bome and skin pathogens to COSs is shown in Table 1. All food-borne pathogens ( $L$. monocytogenes, E. coli, V. parahaemolyticus, and $S$. aureus) exhibited significant susceptibility to COSs $(>10 \mathrm{~mm}$ inhibition diameter). Furthermore, the $E$. coli was more sensitive to COS-citrate than to other COSs. COS-B exhibited the best anti-yeast activity against $C$. albicans and $M$. furfur. On the other hand, acne-inducing skin pathogens such as $P$. acnes, $P$. gramulosum, and $S$. epidermidis, exhibited no significant susceptibility to any COSs. Recently, the antioxidant activity of chitosan and its derivatives has attracted attention due to their nontoxic nature and natural abundance. Therefore, the antioxidant activities of COSs were investigated in DPPH radical scavenging assays and superoxide anion and xanthine oxidase inhibition studies. Fig. 2 depicts the DPPH radical scavenging effect of COS-A, COS-B, COS-H, and COS-citrate. 


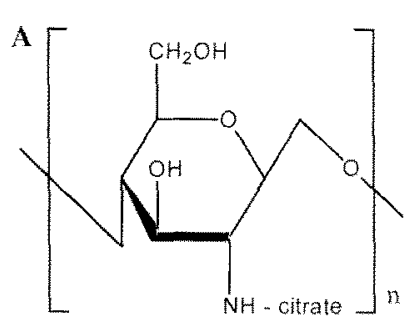

COS-citrate $(n=10 \sim 16)$

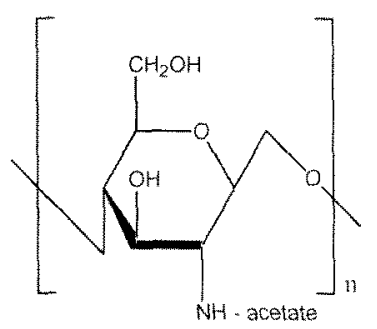

$\operatorname{COS}-A(n>56)$

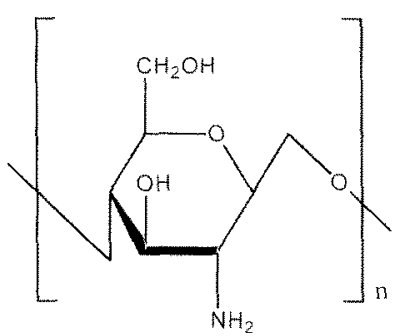

$\operatorname{COS}-H(n=10 \sim 16)$

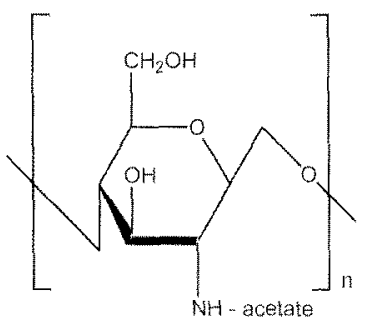

$\operatorname{COS}-B(n=16-55)$

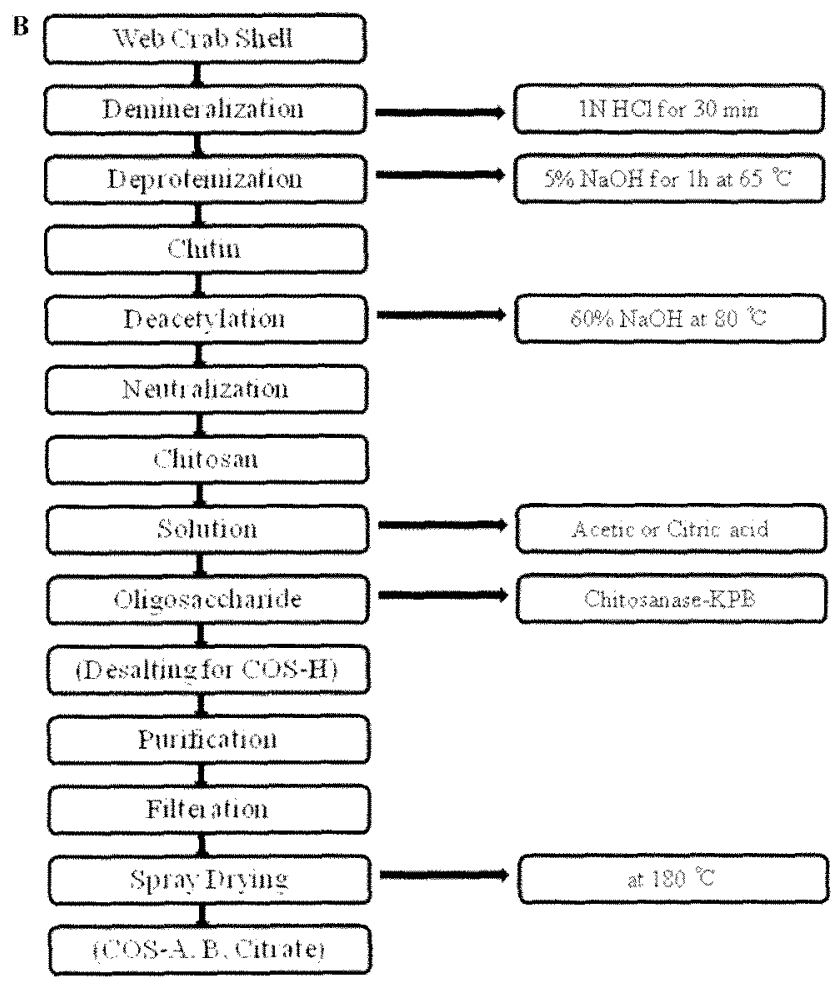

Fig. 1. $\operatorname{COS}$ structures $(A)$ and purification schemes (B). Water-soluble COSs were prepared from $1 \%(w / v)$ chitosan in a dual reactor system. Chitosan $(1 \%, w / v)$ was dissolved in acetic acid. The dual reactor system was composed of a column reactor packed with immobilized chitosanase and an utrafiltration membrane. Chitosan was partialy hydrolyzed using the packed column reactor, and this partially hydrolyzed chitosan was then applied to a substrate feed tank with an ultrafiltration membrane reactor to produce COS-A, COS-B, and COS-H. In COS-citrate, acetic acid was replaced by citric acid.

Table 1. Antimicrobial activity of chitosan oligosaccharides

\begin{tabular}{|c|c|c|c|c|}
\hline Microorganisms & $\operatorname{COS}-\mathrm{A}$ & $\cos -B$ & COS-citrate & $\mathrm{COS}-\mathrm{H}$ \\
\hline Listeria monocytogenes & 12 & 12 & 13 & 10 \\
\hline Staphylococcus aureus & 12 & 12 & 12 & 10 \\
\hline Escherichia coli & 10 & 10 & 14 & 9 \\
\hline Vibrio parahaemolyticus & 11 & 11 & 11 & 9 \\
\hline Propionibacterium acnes & - & - & - & - \\
\hline Propionibacterium granulosum & -. & - & - & - \\
\hline Malassezia furfur & 13 & 15 & 12 & 12 \\
\hline Staplwtococous epidermidis & - & - & - & - \\
\hline Candida albicans & 11 & 13 & 11 & 10 \\
\hline \multicolumn{5}{|c|}{ 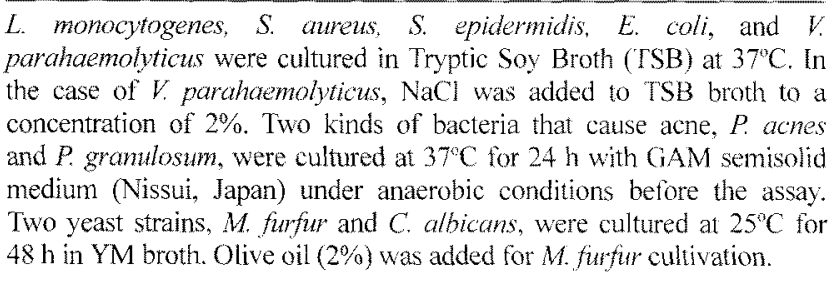 } \\
\hline
\end{tabular}

The DPPH radical scavenging activity increased with increasing concentrations of COSs; in other words, the effect was concentration-dependent. Moreover, as shown in Fig. 2, the 50\% inhibition concentration $\left(\mathrm{IC}_{50}\right)$ of COS-H was $1.56 \mathrm{mg} / \mathrm{mL}$, while the $\mathrm{IC}_{50} \mathrm{~s}$ of the other $\mathrm{COS}$ were above $2 \mathrm{mg} / \mathrm{mL}$. DPPH possesses a proton free radical with a characteristic absorption that decreases significantly on exposure to proton radical

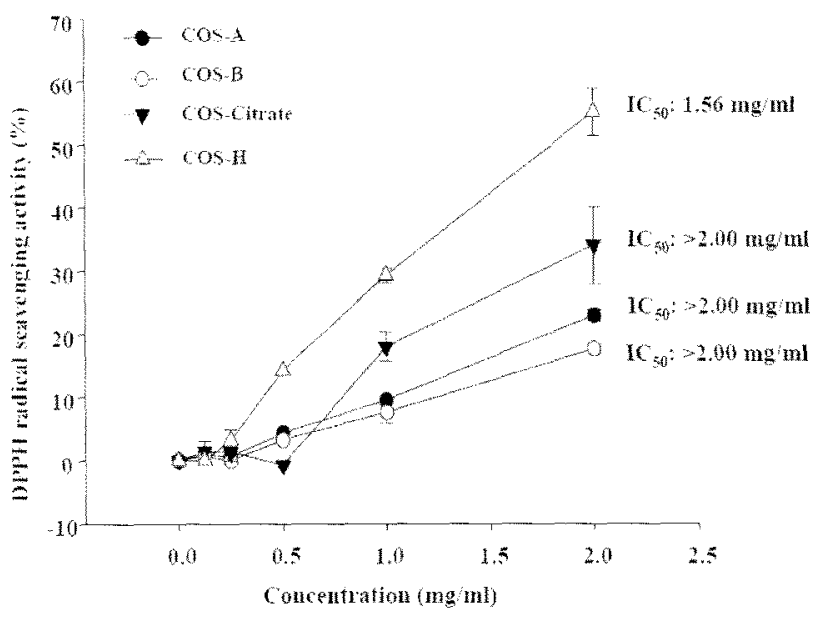

Fig. 2. Free radical scavenging activity of COSs on DPPH radicals. A $4 \times 10^{4} \mathrm{M}$ DPPH solution was prepared in methanol. During the assay, $100 \mu \mathrm{L}$ of chitosan oligosaccharides and $100 \mu \mathrm{L}$ of freshly prepared DPPH solution were thoroughly mixed. The reaction mixture was incubated at room temperature for $20 \mathrm{~min}$. The absorbance was then recorded at $517 \mathrm{~nm}$ using an ELISA reader. The concentration of chitosan oligosaccharides that provided $50 \%$ inhibition $\left(\mathrm{IC}_{\mathrm{S}}\right)$ of the DPPH free radical was calculated from a plot of the inhibition percentage against the COS concentration.

scavengers, and DPPH free radical scavenging by antioxidants is due to their hydrogen-donating ability. Thus, scavenging of DPPH free radical was directly affected by the amount of 


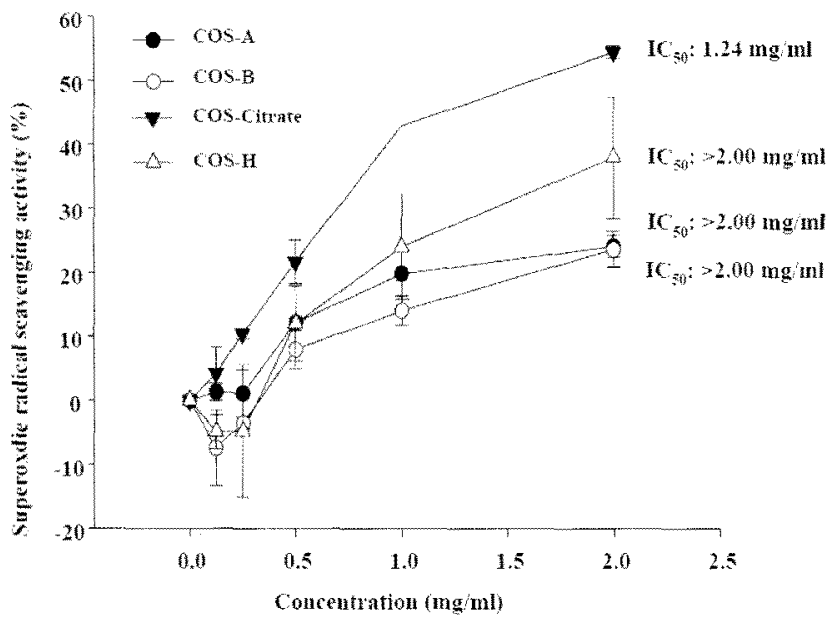

Fig. 3. Free radical scavenging activity of COSs on superoxide anion. Superoxide radicals were generated by the xanthine/xanthine oxidase system and monitored by the production of nitroblue tetrazolium (NBT). Reaction mixtures containing five different concentrations of chitosan oligosaccharide, $0.5 \mathrm{mM}$ xanthine, and 0.5 $\mathrm{mM}$ NBT were incubated at room temperature for $2 \mathrm{~min}$. The reaction was initiated by the addition of xanthine oxidase $(50 \mathrm{mU} / \mathrm{mL})$. After $20 \mathrm{~min}$, the absorbance was recorded at $560 \mathrm{~nm}$ using an ELISA reader. The concentration of chitosan oligosaccharide providing $50 \%$ inhibition $\left(\mathrm{IC}_{50}\right)$ was calculated from a plot of the inhibition percentage against the $\operatorname{COS}$ concentration. The experiments were conducted in triplicate.

attractable atoms in the COSs. Superoxide anion is formed in almost all aerobic cells and is a major agent in the mechanism of oxygen toxicity [Fridovich, 1978; Sawyer and Valentine, 1981; Sun et al., 2004]. Superoxide anion is very harmful to cellular components as a precursor of more reactive oxidative species, such as single oxygen and hydroxyl radicals. Compared with other oxygen radicals, superoxide anion has a longer lifetime, can move longer distances, and is thus more dangerous [Sun $e t$ al., 2008]. Therefore, it is very important to study scavenging of superoxide anion. Fig. 3 shows the superoxide anion scavenging activity of COSs at different concentrations. The scavenging effects of COS-A, COS-B, COS-H, and COS-citrate increased with increasing concentrations. The $\mathrm{IC}_{50}$ of COS-citrate was $1.24 \mathrm{mg} / \mathrm{mL}$, while $\mathrm{IC}_{50} \mathrm{~S}$ of the other COSs were above $2 \mathrm{mg} /$ $\mathrm{mL}$.

Xanthine oxidase can be found at the end of the catabolic sequence of purine nucleotide metabolism in humans and a few other uricotelic species [Rundles and Wyngaarden, 1969]. It catalyzes the oxidation of xanthine, transforming it into uric acid. Overproduction of uric acid can cause hyperuricemia and gout, in which uric acid is deposited in joints where it causes painful inflammation [Rasaratnam and Christophidis, 1995; Harris et al., 1999; Hsieh et al., 2007]. Accordingly, use of a xanthine oxidase inhibitor that blocks the synthesis of uric acid in the body is a potential therapeutic approach for the treatment of gout [Emmerson, 1996; Hsieh et al., 2007]. As mentioned, the conversions of hypoxanthine to xanthine and of xanthine to

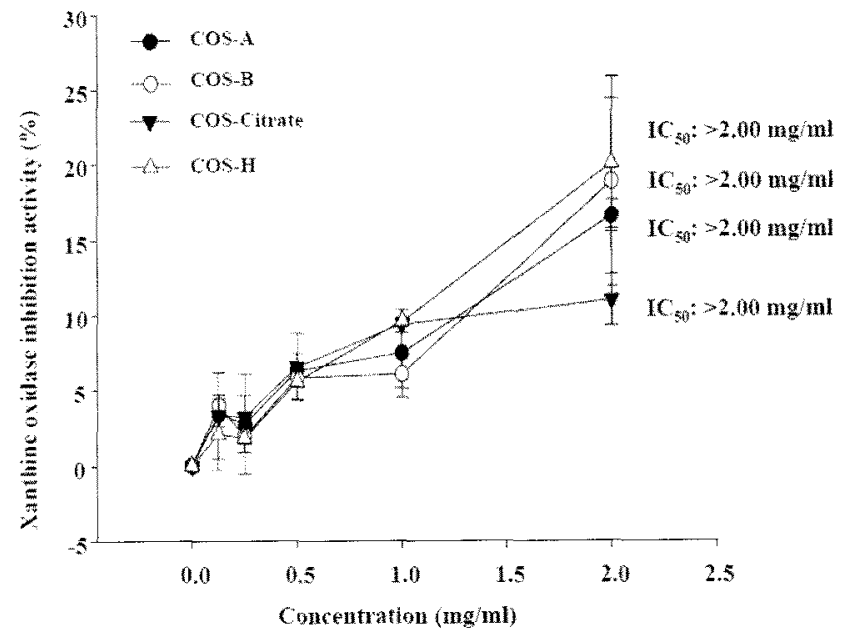

Fig. 4. Inhibition of xanthine oxidase by COSs. Xanthine oxidase inhibition was evaluated by measuring the formation of uric acid from xanthine at room temperature. Reaction mixtures consisted of five different concentrations of the chitosan oligosaccharide in $100 \mu \mathrm{L}$ of $200 \mathrm{mM}$ potassium phosphate buffer $(\mathrm{pH} 7.5)$ containing $1 \mathrm{mM}$ EDTA, $0.5 \mathrm{mM}$ xanthine, and $50 \mathrm{mU} / \mathrm{mL}$ xanthine oxidase. The activity of xanthine oxidase was spectrophotometrically determined by measuring the production of uric acid from xanthine at $290 \mathrm{~nm}$. Activity was expressed as $\mathrm{IC}_{50}$, and was defined as the concentration required to scavenge $50 \%$ of the uric acid in the solution. All experiments were performed in triplicate.

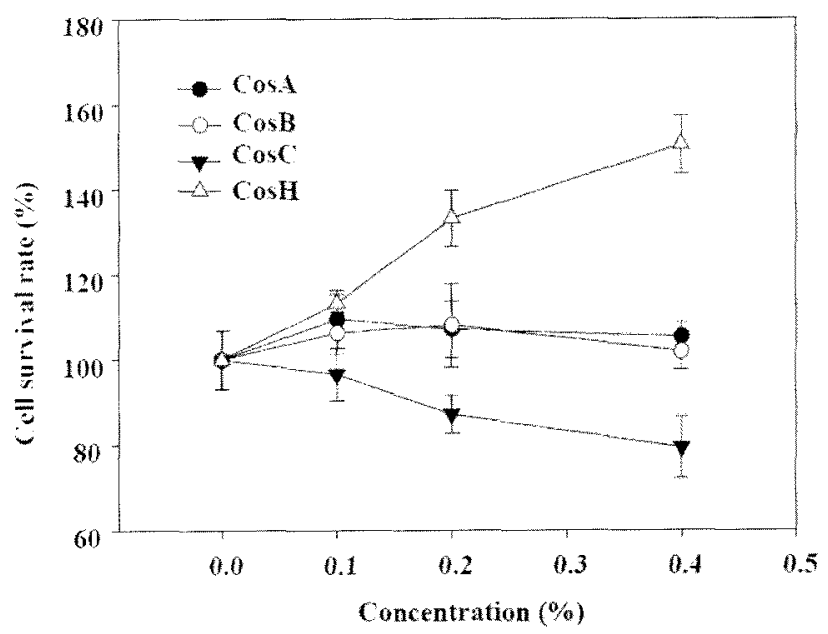

Fig. 5. Cell viabilities of human fibroblast cells treated with COSs. Human fibroblast cells were grown in DMEM supplemented with $10 \%$ (v/v) heat-inactivated FBS, penicillin $(100 \mathrm{U} / \mathrm{mL})$, and streptomycin $(100 \mu \mathrm{g} / \mathrm{mL})$. Cultures were maintained at $37^{\circ} \mathrm{C}$ in $5 \% \mathrm{CO}_{2}$ incubator. Cells were seeded in a 96-well plate at a concentration of $2 \times 10^{4}$ cells/ mL. Sixteen hours after seeding, the cells were treated with the extract samples. The cells were then incubated for an additional $72 \mathrm{~h}$ at $37^{\circ} \mathrm{C}$. MTT stock solution ( $50 \mu \mathrm{L} ; 2 \mathrm{mg} / \mathrm{mL}$ in PBS) was then added to each well for a total reaction volume of $250 \mu \mathrm{L}$. After incubating for $4 \mathrm{~h}$, the plate was centrifuged at $900 \times \mathrm{gg}$ for $10 \mathrm{~min}$ and the supernatant was aspirated. The formazan crystals in each well were dissolved in DMSO. The amount of purple formazan was determined by measuring the absorbance at $540 \mathrm{~nm}$.

uric acid are catalyzed by xanthine oxidase in the breakdown of purines. The inhibition of xanthine oxidase by COSs is shown in Fig. 4 . The inhibitory activity against xanthine oxidase was very low $\left(\mathrm{IC}_{50}>2 \mathrm{mg} / \mathrm{mL}\right)$. The cytotoxic effects of COSs were also 
examined in human fibroblast cells, because COSs could have cytotoxic effects on human skin cells when applied as therapeutic agents. If so, they would not be suitable therapeutic agents. The cell viability was almost $100 \%$ with COS-A, COS$\mathrm{B}$, and $\mathrm{COS}-\mathrm{H}$ at concentrations below $4 \mathrm{mg} / \mathrm{mL}$, whereas human fibroblast cell viability with COS-citrate was over $80 \%$ (Fig. 5). These data suggest that COSs have low cytotoxicity against mammalian cells. In conclusion, the antibacterial and antioxidant activities of the COSs were investigated. These compounds exhibited moderate DPPH scavenging, superoxide radical scavenging, and inhibition of xanthine oxidase. To clarify the antibacterial activities of COSs, we evaluated whether they could inhibit the growth of food-borne and skin pathogens. To test the potential application of COSs as cosmetic materials, we also performed MTT assays on human fibroblast cells. In this assay, COSs did not induce any adverse reactions. Based on these results, we suggest that COSs be considered possible candidates for human health.

Acknowledgments. This research was partially supported by the Regional Technology Innovation Program (RTI04-02-07) and the Research Fund of Small and Medium Business Administration, which are managed by the Ministry of Knowledge and Economy, Korea.

\section{References}

Eaton P, Fernandes JC, Pereira E, Pintado ME, and Xavier Malcata F (2008) Atomic force microscopy study of the antibacterial effects of chitosans on Escherichia coli and Staphylococcus aureus. Ultramicroscopy 108, 1128-1134.

Emmerson BT (1996) The management of gout. New Engl J Med 334, 445-451.

Felt O, Buri P, and Gumy R (1998) Chitosan: a unique polysaccharide for drug delivery. Drug Dev Ind Pharm 24, 979-993.

Fernandes JC, Tavaria FK, Soares JC, Ramos OS, Joâo Monteiro M, Pintado ME, and Xavier Malcata F (2008) Antimicrobial effects of chitosans and chitooligosaccharides, upon Staphylococcus aureus and Escherichia coli, in food model systems. Food Microbiol 25, 922-928.

Fridovich 1 (1978) The biology of oxygen radicals. Science 201, $875-880$

Harris MD, Siegel LB, and Alloway JA (1999) Gout and hypenuricemia. Am Fam Physician 59, 925-934.

Hsieh JF, Wu SH, Yang YL, Choong KF, and Chen ST (2007) The screening and characterization of 6-aminopurine-based xanthine oxidase inhibitors. Bioorg Med Chem 15, 3450-2456.

Jeon YJ, Park PJ, and Kim SK (2001) Antimicrobial effect of chitooligosaccharides produced by bioreactor: Carbohydr Polymer 44, 71-76.

Lee HW, Park YS, Jung JS, and Shin WS (2002) Chitosan oligosaccharides, dp 2-8, have prebiotic effect on the Bifidobacterium bifidium and Lactobacillus sp. Anaerobe 8, 319-324.

Lin B, Liu WS, Han BQ, and Sun YY (2007) Antidiabetic effects of chitooligosaccharides on pancreatic islet cells in streptozotocin-induced diabetic rats. World $J$ Gastroenterol 13, $725-731$.

Liu XF, Guan YL, Yang DZ, Li Z, and Yao KD (2001) Antibacterial action of chitosan and carboxymethylated chitosan. J Appl Polymer Sci 79, 1324-1335.

Qin C, Li H, Xiao Q, Liu Y, Zhu J, and Du Y (2006) Watersolubility of chitosan and its antimicrobial activity. Carbohydr Polymer 63, 367-374.

Rasaratnam I and Christophidis N (1995) Gout: 'a disease of plenty'. Aust Fam Physician 24, 849-851.

Rundles RW and Wyngaarden JB (1969) Drugs and uric acid. Anmu Rev Pharmacol 9, 345-362.

Sawyer DT and Valentine IS (1981) How super is superoxide? Acc Chem Res 14, 393-400.

Seo S, King JM, and Prinyawiwatkul W (2007) Simultaneous depolymerization and decolorization of chitosan by ozone treatment. $J$ Food Sci 72, C522-526.

Seyfarth F, Schliemann S, Elsner P, and Hipler UC (2008) Antifungal effect of high- and low-molecular-weight chitosan hydrochloride, carboxymethyl chitosan, chitosan oligosaccharide and N-acetyl-D-glucosamine against Candida albicans, Candida krusei and Candida glabrata. Int J Pharm 353, 139148.

Shahidi F, Arachchi JKV, and Jeon YJ (1999) Food applications of chitin and chitosans. Trend Food Sci Technol 10, 37-51.

Sun T, Xie W, and Xu P (2004) Superoxide anion scavenging activity of graft chitosan derivatives. Carbohydr Polymer 58, 379-382.

Sun T, Yao Q, Zhou D, and Mao F (2008) Antioxidant activity of $\mathrm{N}$-carboxymethyl chitosan oligosaccharides. Bioorg Med Chem Lett 18, 5774 5776.

Zheng LY and Zhu JF (2003) Study on antimicrobial activity of chitosan with different molecular weights. Carbohydr Polymer 54, 527-530. 